\title{
Construir e legitimar a autoridade paterna e comunal em um processo em São Severino (Marcha de Ancona) na metade do Século $\mathrm{XV}^{*}$
}

Didier Lett ${ }^{*}$

Resumo: Em agosto de 1458, em São Severino, nas Marchas de Ancona, durante um gioco della battagliosa, batalha de pedras, durante a qual, de maneira ritualizada, as crianças da cidade enfrentavam-se, uma criança foi gravemente ferida. O pai da vítima iniciou um processo inquisitorial obrigando o pai do acusado a comparecer em juízo, com testemunhas, para defender seu filho e provar, dentre outras coisas, que ele tinha menos de dez anos e, por isso, era inimputável. Esta defesa paterna permite constatar que para proteger seus próximos os atores sociais utilizam as normas estatutárias e procedimentos jurídicos em exercício na comuna.

* Texto inédito, previsto para publicação em francês em: La légitimité implicite tome 1 de la collection Le pouvoir symbolique en Occident (v.1300-v.1640) Pour une sémantique de l'État, Jean-Philippe Genet dir., Paris-Rome, Publications de la Sorbonne et École française de Rome, 2014. Tradução: Igor Salomão Teixeira.

** Professor de História Medieval na Universidade de Paris Denis-Diderot (Paris 7). Doutor em História (EHESS, 1995, e habilitado para dirigir pesquisas (Paris 1 - Sorbonne, 2006). Especialista em história da infância, das relações intrafamiliares e da paternidade na Idade Média, principalmente entre os séculos XII e XIV; hagiografia medieval (milagres e processos de canonização); história de gênero e das categorias sociais; história das Marcas (Itália) no século XIV. De sua autoria: L'Enfant des miracles: enfance et société au Moyen Âge (XIIe-XIIIe siècle) publicada em 1997; Famile et parenté dans l'Occident médiéval (Ve-XVe siècles), publicada em 2000; Un procès de canonisation au moyen âge: essai d'bistoire sociale. Nicolas de Tolentino, 1325 (2008) e, mais recentemente, Frères et soeurs: bistoire d'un lien (2009). Este é seu primeiro texto em língua portuguesa. E-mail:didier.lett@wanadoo.fr.

Anos 90, Porto Alegre, v. 20, n. 38, p. 249-270, dez. 2013 
Construir e legitimar a autoridade paterna e comunal em um processo...

Permite igualmente observar as manifestações de diferentes figuras de autoridade e instâncias de legitimação implícitas ou explícitas. Esse tipo de acontecimento constrói a autoridade paterna e a autoridade comunal. Este estudo de micro-história permite também analisar, em uma determinada sociedade, o conjunto das representações, das regras de conduta, dos valores associados aos indivíduos ou às ações como princípios componentes dos ideais da vida social. Permite, ainda, rever a pertinência de uma oposição rígida entre normas e práticas.

Palavras-chave: Itália. Autoridade. Normas/práticas.

\section{Introdução}

Em agosto de 1458, em São Severino, na Marcha de Ancona, durante um gioco della battagliola, batalha de pedras no curso da qual, de maneira ritualizada, as crianças (e talvez os adultos) da vila enfrentavam-se, Benincasa di Beneamato Corradi, fere gravemente a cabeça de outra criança, Andrea di Nicola, por tiro de pedra, com a ajuda de uma funda (espécie de estilingue) e ocasiona uma fratura de crânio com uma grande efusão de sangue ${ }^{1}$. Nicola di Andrea, o pai da vítima, inicia uma querela e em 16 de setembro de 1458 foi aberto um processo (inquisitio) pelo podesta de São Severino, Antonio de Salamacchi de Citta di Castello, e seu juiz (judex malleficiorum) contra a criança culpável, Benincasa. Imediatamente, um núncio é enviado à casa do acusado para intimar a comparecer diante do juiz. Como o acusado não apareceu, em 22 de setembro, o juiz ordena ao pregoeiro a proclamar o banimento de Benincasa de São Severino e de seu território, além de reclamar o pagamento de uma multa de cem livros, se a criança não se apresentar em três dias. Em 25 de setembro, não foi o filho que compareceu, mas o pai, Beneamato. Ele produziu um rescrito pontifício (supplicatio cum rescriptio), datado de 22 de setembro, obtido com o notário apostólico Stefano Nardini de Forlì, vicário da Marcha de Ancona. Nesse documento, dois elementos novos aparecem que são colocados em evidência para evitar o exílio do filho e a multa do pai: a idade da criança, que "não atingiu a idade de 10 anos $^{2 \prime}$ e a pobreza do pai do culpável que não pode pagar aquela soma. Considerando que Benincasa é menor e que os acidentes ocorridos durante as battaglie não são punidos, o notário apostólico pede ao podesta que a querela seja anulada e que

Anos 90, Porto Alegre, v. 20, n. 38, p. 249-270, dez. 2013 
não seja dado continuidade. Dois dias mais tarde, em 27 de setembro, Beneamato apresenta uma lista de dez artigos ao podesta para que ele interrogue testemunhas. O pedido foi aceito: seis testemunhas (cinco homens e uma mulher, a mãe da criança) foram convocadas e interrogadas, no dia 4 de outubro. Infelizmente, para nós, o mandato do podesta chegou ao fim. Ele deixou sua função antes de pronunciar a pena. Em novembro de 1458, seu sucessor, Simone de Ranieri de Nocia, julgou esse caso, mas as atas dos procedimentos não foram conservadas. Nunca conheceremos o fim da história.

Esse "pequeno processo" permite estudar os procedimentos adotados por um pai para defender seu filho, observar as manifestações de diversas figuras de autoridade e de colocar em evidência as diversas instâncias de legitimação implícitas ou explícitas. A querela iniciada pelo pai da vítima, sua recepção junto às autoridades comunais e depois a ação do pai do acusado e o desenvolvimento do processo inquisitorial na sequência são os vetores de legitimação da autoridade paterna, certamente fundada sobre o direito, mas que se atualiza na interação. Esse tipo de acontecimento constrói, assim, a autoridade paterna, a autoridade comunal da quasi città de São Severino, desde que os pais apelem e passem para os dirigentes (o podesta, o juiz) e a autoridade soberana pontifical (São Severino encontra-se na Marcha de Ancona e pertence ao Estado Pontifício). Esse estudo de caso permite, também, revelar, em uma dada sociedade, o conjunto das representações, das regras de conduta, dos valores ligados aos indivíduos ou às ações, sucintamente, os principais componentes dos "ideais" da vida social, segundo Maurice Godelier. Uma vez que temos também a sorte de ter conservada uma rubrica dos estatutos de São Severino relativa aos jogos de battaglia datada de 1426. Esse "pequeno processo" permite, enfim, mostrar que os atores sociais possuem um bom conhecimento da lei, das normas estatutárias. Podemos, então, estudar a maneira pela qual, para denunciar ou para se defender, eles escolheram os argumentos que deveriam fundamentar sua legitimidade. Como mostrou Luc Boltanski em particular, a competência dos sujeitos sociais face a justiça não reside unicamente na sua capacidade de manipular as normas, mas em sua aptidão de bem conhecer os procedimentos de legitimação de seus próprios argumentos (BOLTANSKI, 1990). 
Construir e legitimar a autoridade paterna e comunal em um processo...

\section{Fazer justiça e o jogo de pedras na Marca de Ancona no século XV}

Quando desse acontecimento, a comuna de São Severino, como o conjunto das Marca, estava no governo o ambicioso condottiere Francesco Sforza, que tinha sido nomeado marquês de Ancona e "gonfalonier" da Igreja, de 1433 a 1447 (MANSELLI, 1981, p. 224260; WALEY, 1978, p. 229-320; JANSEN, 2001, p. 94-99, 2003, p. 195-218; GIANANDREA, 1978, p. 8-13, p. 105-110). A partir do reinado de Nicolau V (1447-1455), a monarquia pontifícia restabeleceu progressivamente seu poder sobre as Marcas. Após diversas peripécias, a cúria reinstalou-se em Macerata, em 1451. Desde então, as comunas retornaram para uma situação que tinha sido estabelecida pelas Constituições de Albornoz (1357), que autorizava o reitor pontifício, em tese, a intervir em três domínios que limitavam a autonomia das comunas: a redação dos estatutos locais, a nomeação dos oficiais comunais e o exercício da justiça. O reitor possui o merum et mixtum imperium, isto é, o conjunto de poderes de justiça penal alta e baixa. De fato, as comunas permaneceram relativamente autônomas em matéria de justiça. Mas, como evidencia aqui o rescrito com o qual Beneamato compareceu, os sujeitos entendiam completamente a possibilidade de reclamar às instâncias pontifícias.

As cidades-Estados e os Estados territoriais italianos representam um excelente terreno de pesquisa para o estudo das formas e dos instrumentos da repressão penal e dos modos infrajudiciários de solução dos conflitos (ZORZI, 1998). Nessas comunas mercantis, como quase todos os lugares na Itália, a bataglia, batagliola, guerra, proelium, ou, ainda, pugna, bellum, ludus eram atividades profundamente enraizadas. Mesmo se existiam períodos do ano mais propícios (Carnaval), as batalhas de pedras aconteciam durante todo o ano. Elas atingiam todos os meios sociais, as crianças e os adultos. Esses jogos ritualizados são paramilitares, no sentido de que eles podiam também aparecer como uma preparação à guerra, ou, ao menos, para a defesa da cidade. Eles desempenham um papel de socialização coletiva de grupos etários e consideram, também, a possibilidade de competição entre bairros (ZORZI, 1993, p. 71-107; TADDEL, 2001, p. 119-132; SETTIA, 1990, p. 79-105;

Anos 90, Porto Alegre, v. 20, n. 38, p. 249-270, dez. 2013 
IMBUCCI, 1999; CAVACIOCCHI, 1995; RIZZI, 2000, p. 47-64; 1995). As autoridades comunais adotaram uma atitude ambígua face a esses jogos de pedras. Sob a pressão para certa moralização da sociedade, para a qual a pregação mendicante não era estranha, elas colocaram limites a essas batalhas, tentando restringi-las a lugares específicos (de preferência, extramuros), para atenuar a violência (proibição de algumas armas) e de proibir aos adultos. Mas, os casos de proibição pura e simples foram excepcionais, pois essas manifestações faziam parte integrante dos rituais coletivos cívicos que dão coesão a uma comunidade e que permitem de canalizar a violência citadina. Essa atitude explica-se também pela dificuldade de definir o que é verdadeiramente "batalha de pedras": um jogo ou uma verdadeira guerra entre os citadinos? Assistimos, durante o século XV, a um processo de "disciplinarização" jurídica dos jogos, facilmente observável na legislação estatutária, sobretudo se eles representam, como é o caso, graves perigos: em 1291, em Siena, contamos dez mortes durante uma battaglia. (SETTIA, 1990, p.124). É importante para preservar a ordem pública (essas batalhas podiam desencadear "tumultos") e a moral cristã, razão pela qual as atividades lúdicas, principalmente as que utilizavam armas (lança, faca, funda), e os jogos de azar, eram visados pela legislação estatutária ${ }^{4}$. Mas limitar a periculosidade não significa, mesmo ainda no século XV, eliminar completamente um ritual antigo: "Acabar com a battaglie parecia uma empreitada desesperada" (ORTALLI apud CAVACIOCCHI, 1995, p. 46)

\section{Sistema documental e circularidade}

Não podemos analisar e compreender esses pequenos processos, muito numerosos nos arquivos comunais italianos, no seio dos registros do podesta ou do capitão do povo, sem examinar com atenção maior a legislação estatutária (na ocorrência de numerosas rubricas, inclusive no livro De maleficiis), que constitui o fundamento jurídico, e que permite analisar o desenvolvimento do processo penal e a aplicação de sanções. Um dos aspectos mais marcantes desse processo reside na maneira como o pai do acusado e as testemunhas 
que ele convoca se servem das normas estatutárias no seio do inquérito, em particular, para provar a idade da criança e o lugar do jogo. $\mathrm{Na}$ Itália comunal do final da Idade Média, coloca-se em evidência um "sistema documental" crescentemente complexo e, consequentemente, de laços estreitos e uma circularidade entre todas as formas documentais produzidas pelas instâncias comunais (CAMMAROSANO, 2000; BAIET'TO, 2002, p. 645-679). É partindo dos fluxos documentais e não de uma tipologia preestabelecida e dependente da maneira com a qual os historiadores reagruparam os textos da Idade Média que podemos mostrar o laço entre transformações sociais e modificações da organização dos documentos. Os comportamentos dos atores e das atrizes criam exigências políticas e sociais que impõem a adoção de um tipo de organização documental por parte das autoridades comunais que, por conseguinte, tem consequências sobre o comportamento ou sobre os modos de representação (a lista, por exemplo) dos habitantes. Essa circularidade entre os diferentes tipos documentais obriga-nos, também, a reconsiderar o aspecto "normativo" dos estatutos. Para muitos historiadores e historiadores do direito, de fato, os textos estatutários representariam uma norma mais ou menos rígida pela qual o notário, o juiz, o podesta ou o prior em exercício, em sua prática cotidiana, referia-se. Face a esta "fonte normativa", as atas notariais, os inquéritos e as sentenças publicadas pelos tribunais comunais, assim como as deliberações dos conselhos municipais, representariam os "atos da prática", mais próximos da "realidade" que os estatutos. Teríamos, assim, de um lado, as normas que teriam por função propor os quadros e, de outro, as práticas dos atores que contornariam, manipulariam essa norma conhecida. É conveniente, e o exemplo que nós estudamos procura ilustrar isso, recolocar em questão essa découpage facilmente admitida e tentar ver em qual medida as fontes estatutárias, centradas sobre os usos locais, profundamente ancoradas em um território, não davam, elas também, acesso a uma forma de conhecimento das práticas mais próxima dos atores. Se quisermos admitir a importância da mediação notarial e a ideia que todo documento é um filtro (a única realidade histórica que nos resta) entre o que se passou e o que o historiador tenta presentificar, é claro que uma ata notarial, o argumento de um representante de uma região diante de uma deliberação comunal, ou 
a palavra de um testemunho no quadro de uma inquisitio, não são mais próximos da realidade que os estatutos comunais. É preciso, sobretudo, admitir uma interpenetração constante entre todos esses documentos, uma grande porosidade, mesmo que sejam frequentemente os mesmos atores (a elite comunal) que os produzem. $\mathrm{O}$ notário, nessas atas, e as pessoas próximas no momento do registro conhecem perfeitamente os estatutos. As normas estatutárias servem igualmente para legitimar as práticas e aparecem, então, como um meio de tentar organizar o real, de transformá-lo em um caso mais ou menos de sucesso. "Podemos mesmo afirmar que toda a matéria penal é, de fato, regrada pelas normas estatutárias, próprias a cada cidade e caracterizadas por uma dimensão puramente factual: o estatuto citadino realiza a máxima de Baldo, segundo a qual jus facto oritur" 5 (MAFFEI, 2007, p. 21).

Para quebrar essa oposição, parece-nos que um dos melhores ângulos de ataque consiste, em uma ótica micro-histórica, em confrontar sistematicamente sobre um tema específico, a produção e o uso desses tipos diversos de documentação, como no caso da ocorrência apresentada aqui de uma rubrica do estatuto e um "pequeno processo" julgado pela corte do podesta. Como escreveu Paolo Cammarosano, em 1991: “Quem analisa um texto estatutário deve, desde o início, procurar reconstruir a posição e dinâmica no tempo, a relação com os outros elementos do quatro institucional, a articulação no interior de um sistema de relações territoriais" (CAMMAROSANO, 1991, p. 156). No cotidiano comunal, a referência aos estatutos era muito frequente. No caso que analisamos neste texto, no momento em que o processo inquisitorial entra em cena, o notário escreveu que aquele era o fato "[...] formam juris satutorum, ordinamentorum dicte terre" (ASCS, Liber mallefitiorum, fol. 204). Na forma, certamente, mas também no conteúdo das perguntas (articuli) e das respostas das testemunhas, as normas estatutárias estão presentes no seio dos pequenos processos comunais. 
Construir e legitimar a autoridade paterna e comunal em um processo...

\section{Uma rubrica em três estratos sobre os jogos de crianças nos estatutos de 1426}

Os estatutos conservados de São Severino foram redigidos em 1426. São o fruto de uma (re)elaboração no quadro de uma nova legislação lançada após o banimento, pelo papa, dos Smeducci família local de mercenários (guelfos, mas, sobretudo, oportunistas) - que dominou a cidade durante o século XIV após ter sido cassada pelos exércitos de Antonio Colonna e de Caldora. Nesses estatutos uma rubrica do Livro II (De maleficiis) tem o título seguinte: "Quod pueri et alii non faciant ad prelium". " Ela comporta três partes que podem parecer contraditórias se não considerarmos no conteúdo dessa rubrica uma cronologia, três estratos de elaboração, três intervenções legislativas sucessivas. É importante, então, considerar que somente o estrato inferior, o último a ser adicionado, data de 1426, e que os dois outros são anteriores a esta data, mas que as três partes foram copiadas em sequência, da mais antiga à mais recente, naquele ano. Os especialistas dos statuti não foram suficientemente atentos sobre a origem e o caráter evolutivo da legislação estatutária. A matéria original a partir da qual foram redigidos os primeiros estatutos é formada por ordenações de cônsules (breve consulum) de sentenças do podesta ou de outros magistrados comunais. Desde a origem, então, o estatuto é composto por "atos da prática”. Uma vez elaborados, esses estatutos foram submetidos frequentemente a correções e a acréscimos que deixam traços nos manuscritos: correções, adições nas margens ${ }^{7}$ ou, talvez, acréscimos sobre os fólios não utilizados, "em branco", ao final do manuscrito. Essas numerosas correctiones e frequentes additiones impõem pesadas dificuldades para a datação. Elas são irregulares. Alguns momentos (como no caso analisado aqui, uma modificação de família dominante) foram mais propícios que outros para a multiplicação das modificações, ou, ainda, algumas rubricas resistiam mais que outras às transformações. Em tese, as comissões de statutores eram encarregadas, em intervalos mais ou menos regulares, de revisar os estatutos levando em consideração a evolução da conjuntura, acontecimentos particulares. É importante, então, procurar as razões dessas modificações nas justificativas eventualmente elaboradas pe- 
los legisladores ou tentando reconstituir as causas das modificações em comparação com as versões de estatutos conservados. ${ }^{8}$

A primeira parte (a mais antiga) da rubrica dos estatutos de 1426 proíbe as crianças e qualquer outra pessoa (pueri nec aliquis alius) de fazer uma batalha de pedras (prelium on bactalia) com a mão ou com uma funda (cum gecta vel mazaflonna), na zona suburbana chamada grave Potentie (margem de Potenza, rio que passa por São Severino) nem perto dos moinhos, nem perto de outros edifícios que se encontrem ao longo da margem do rio (atual Borgo Conce) ${ }^{9}$. Lendo essa passagem (e o título do livro da rubrica), podemos, então, deduzir que, no século XV, em São Severino, os principais atores daqueles jogos eram as crianças, mas não exclusivamente. $\mathrm{O}$ lugar mencionado deveria oferecer às crianças um excelente terreno de jogo ou de enfrentamento e um espaço com muitos projéteis. Mas esse espaço ao longo de Potenza representa também um centro econômico essencial da comuna onde foram instalados os moinhos e os ateliês de lã, couro e pergaminho e era, então, imperativo proteger das eventuais depredações que podiam ser provocadas pelas batalhas. Podemos evocar a hipótese de que em todos os outros lugares da cidade esta atividade era autorizada. Geralmente, as batalhas localizam-se em um espaço suburbano (mais comumente em um prado). Em Perúgia, no final da Idade Média, existia o Campo de Batalha (campus battaglie), lugar destinado às batalhas de pedras, mesmo se o jogo acontecesse em outros lugares (MAIRE VIGUEUR, 1992, p. 199), Ao final dessa primeira parte da rubrica, é definido que o condenado deveria pagar à comuna uma multa de cinco soldos, que o pai deveria converter essa soma para seu filho menor (desde que menor de vinte cinco anos) ${ }^{10}$ e que cada cidadão era convidado a denunciar os contraventores com garantia de anonimato e de que embolsaria a metade da multa.

Os dois acréscimos de algumas linhas dizem respeito apenas à idade da responsabilidade do condenado ${ }^{11}$. A segunda parte decreta que o podesta e seus oficiais não podem perseguir penalmente as crianças menores de quatorze anos (pueri minores quatuordecim annis). A terceira e última parte (acrescida posteriormente, sem dúvida, no momento da redação dos estatutos, em 1426), diminui a idade da imunidade do culpável para dez anos, desde que as crianças entre

Anos 90, Porto Alegre, v. 20, n. 38, p. 249-270, dez. 2013 
Construir e legitimar a autoridade paterna e comunal em um processo...

dez e quatorze anos (pueri a decem annis supra usque ad quoartumdecimum annum) sejam também punidas com mais da metade da pena. As crianças menores de dez anos não podiam, então, ser perseguidas: "a decem annis infra ad nullam penam teneantur". Consequentemente, a norma estatutária relativa a esses jogos, em vigor no momento do acidente de 1458, estipula que os indivíduos de mais de quatorze anos deveriam pagar uma multa de cinco soldos, os que tivessem entre dez e quatorze, uma multa de dois soldos e meio e os que tivessem menos de dez anos não pagariam nada. Compreendemos que um dos objetivos do pai (e, então, das testemunhas convocadas) seria provar que a criança acusada tinha menos de dez anos.

Três elementos podem ser observados a propósito dessas "normas". Inicialmente, o "Addimus" do estatuto soa como uma adaptação das normas à prática, uma atualização, e corrobora o fato de que a oposição entre normas e práticas é pouco operante para ler o social. Também, as sanções variam em função da idade em quase todos os estatutos. No curso dos séculos XIV e XV, assistimos a uma dupla evolução: de um lado, uma tendência de proibir esse tipo de atividade aos adultos e aos adolescentes, liberando (e controlando) as batalhas para crianças e, de outro lado, como podemos ler claramente nesses três estratos sucessivos, uma tendência à diminuição da idade autorizada a jogar e da idade passível de ser considerada como responsável. Nas comunas, existe uma impunidade total para os menores, mas a idade é inferior a sete anos em Alessandria, dez anos em Como e em Mondovi, doze anos em Treviso e em Tivoli etc. ${ }^{12}$ Nesses casos de irresponsabilidade pueril, a multa deveria ser paga pelo pai ou pelo tutor. No século XV, quase em todos os lugares, os indivíduos maiores de doze ou quatorze anos eram considerados responsáveis penalmente, mesmo considerando a existência de tarifas graduais até os vinte ou vinte e cinco anos. Enfim, em nenhum momento, o legislador dessa rubrica de 1426 condena esses jogos de crianças, que não são nunca considerados, em si, como ilícitos. 


\section{O uso dos estatutos em um processo inquisitorial}

Os dois aspectos que estão no centro das normas estatutárias de 1426 e que, então, fazem ou fizeram o debate na cidade são sobre os lugares da batalha e sobretudo (objeto dos dois acréscimos) a idade do imputável. Eles têm igualmente um lugar capital nos articuli elaborados por Beneameto. Este procura provar que a batalha se desenvolveu em um lugar autorizado e sobretudo que seu filho não tinha a idade de dez anos. Os atores sociais (o pai, a mãe e os outros pais que testemunharam) conhecem perfeitamente os estatutos. Isso pode ser pelo fato de nas numerosas comunas italianas do final da Idade Média uma cópia desses estatutos se encontra à disposição dos habitantes na entrada do palácio comunal ou da igreja, fixada a uma grade.

A argumentação do pai consiste em provar aos olhos das autoridades comunais e da coletividade, de seus "pares", que seu filho não cometeu uma "falta gramatical" no sentido de uma diferença de comportamento em relação ao que está escrito nas normas. Se, como propõe Cyril Lemieux, as ações dos homens podem ser lidas utilizando a noção de "gramática", os statuti devem ser considerados como exigências gramaticais às quais os indivíduos da comunidade regida por esses estatutos devem se conformar. Mas existe uma série de "faltas gramaticais" nas quais o princípio da evidência é percebido através das normas, mas também através dos comportamentos, as práticas. Recorrer à regra para mostrar que houve uma falta de comportamento permite à regra se atualizar na vida social (LEMIEUX, 2009, p. 37).

Seis testemunhas foram convocadas: Thomas di Sassolino, Ansovino di Severino, Nicola de Oliviero, Lucarello di Bartholomeo, Vittorino di Giovanni et domina Bartholomea, esposa de Beneamato. Observando atentamente o fólio 205v, sobre o qual figuram os nomes das testemunhas seguidas pela lista dos articuli, podemos deduzir inicialmente que quatro testemunhas somente foram abordadas e que as outras duas foram adicionadas posteriormente. De fato, os nomes de Thomas de Sassolino, Ansovino di Severino, Vittorino di Giovanni e Nicola di Oliviero aparecem em uma mesma linha de escrita, diferentemente do restante do texto. Eles são enquadrados por duas chaves $(\{\})$. Atrás da chave 
Construir e legitimar a autoridade paterna e comunal em um processo...

da esquerda, podemos ler "testes" e atrás da chave da direita, "testes ad probandum predicta". Em toda essa pequena linha de escrita (sem dúvida, redigida pela mesma mão que redigiu o conjunto), à falta de espaço, foram acrescentados, embaixo, o nome da mãe da criança e, mais abaixo, aquele de Lucarello di Bartholomeo. Como veremos adiante, essas duas pessoas "acrescentadas" são as duas testemunhas mais precisas sobre a idade de Benincasa.

As seis testemunhas foram interrogadas sobre dez artigos. $\mathrm{O}$ primeiro artigo é sobre a inquisição contra Benincasa que, segundo seu pai, não estava conforme as leis em vigor. As testemunhas não respondem a esta questão jurídica (obmisso primo). Eles foram certamente convocados para defender Beneamato, mas não se autorizam a portar um julgamento sobre a maneira pela qual as instâncias judiciárias de sua comuna aplicam a lei. $\mathrm{O}$ segundo artigo indica que em São Severino, desde tempos imemoriais (a multis annis citra in cuius contrarium memoria), a maioria das crianças da comuna entregam-se a esse gênero de batalha. Lucarello di Bartholomeo confirma que essa é praticada há muito tempo (ab antiquo). Thomas di Sassolino afirma que:

[...] em São Severino, nós sempre tivemos o hábito de fazer as batalhas de pedras entre as crianças e que sempre houve ferimentos durante esses jogos. Jamais ouvi dizer que devemos pagar por isso! Acrescento que uma pessoa da cidade foi morta durante um desses jogos de pedras e nunca houve um processo contra o culpado. Eu mesmo fui ferido em uma dessas batalhas e nenhuma sanção foi aplicada contra meu agressor ${ }^{13}$ (ASCS, Liber mallefitiorum, folio 206).

Vittorino di Giovanni disse sensivelmente a mesma coisa: sempre houve muitos feridos e nenhuma pena. Ansovino di Severino e Nicola de Oliviero acrescentam que, em seus tempos, as partidas não acabavam. A partir dessas respostas, constatamos como os atores acreditavam numa mitologia (isso sempre foi assim!) em um sistema de defesa. Como os "interlocutores" da antropologia crítica, eles são considerados atores históricos que constroem narrativas que têm aparência de um mito, mas que são, a cada vez, enunciados 
diferentemente, em função do contexto de produção: eles não diriam a mesma coisa se tivessem que testemunhar em outro contexto e utilizar outros argumentos de defesa ${ }^{14}$ (BAZIN, 1979a, p. 435-484; 2008, p. 51-98; BENSA, 2006, p. 123-138, CHAUVIER, 2011). Notamos também o quanto as testemunhas sentem-se "em seu direito", pois é seguidamente admitido, talvez mesmo dentro da lei, que aquele que mata ou que fere durante uma battaglia pode ficar impune. ${ }^{15}$

Em relação às respostas ao terceiro artigo, é preciso provar que durante o mês de agosto daquele ano houve uma battaglia entre muitas crianças de São Severino. Três testemunhas sobre seis responderam a mesma coisa (ou, ao menos, o notário enquadrou pequenas diferenças entre os depoimentos em uma fórmula): muitas batalhas aconteceram durante aquele mês. ${ }^{16} \mathrm{O}$ quarto ponto é essencial: é preciso comprovar que o acidente aconteceu durante a batalha (in prelio) e não à margem desta. Nicola di Oliviero precisa que o drama aconteceu fora da cidade, perto da Porta della Valle (atualmente, porta Sette Cannelle) delimitando o espaço que ele nomeia (respondendo às injunções do notário? Ou o notário acrescentou ele mesmo esses confrontos? $)^{17}$. Nomear com precisão o lugar da batalha de agosto de 1458 é um meio implícito e eficaz de indicar a prova que o jogo não aconteceu em local proibido (a grave Potentie) pelos estatutos de 1426. Ansovino di Severino explica que ele tomou conhecimento do acidente, pois ele ouviu as vozes alteradas de algumas crianças que gritavam (anotado em língua vulgar): "Algodão, algodão, o filho de Nicolas foi ferido!"'18. Respondendo ao quinto artigo, a testemunha deve portar a prova que, na ocasião dessa batalha, outras crianças foram feridas por causa das pedras. Ansovino, Lucarello e Vittorino assim atestaram. Vittorino precisa, inclusive, o nome de outra criança ferida (um certo Evangelista di Giovanni di Asciarello). No sexto artigo, as testemunhas devem confirmar que, em geral, quando há feridos nessas batalhas, o jogo não prossegue. Todos confirmam. Nicola di Oliviero explica, nesse momento do interrogatório, que ele foi ferido durante uma dessas batalhas e que ninguém pagou multa.

Os artigos sete e oito são os mais importantes no sistema de defesa organizado por Beneamato, pois eles são centrados na idade de Benincasa. A mãe da criança foi interrogada apenas com base nesses dois artigos. Nas fontes inquisitoriais, as provas de idade são 
Construir e legitimar a autoridade paterna e comunal em um processo...

sempre interessantes para observar as "âncoras" da memória (BEDELL, 1999, p. 3-27). Ansovino afirma que Benincasa tem menos de dez anos, pois quando ele se casou, oito anos antes, a mãe da criança participou das bodas com um bebê nos braços e que esse bebê não tinha dois anos. ${ }^{19}$ As duas testemunhas que se mostraram mais precisas sobre a idade da criança foram as duas pessoas "acrescidas", as únicas a dar o mês e o ano de nascimento de Benincasa. Lucarello di Bartolomeo confirmou que Benincasa tinha menos de dez anos, pois ele se lembra de seu nascimento, em junho de 1449: sua esposa visitou a parturiente que se encontrava ainda no leito ${ }^{20}$. Segundo esse testemunho, Benincasa tinha, então, nove anos, em junho de 1458, dois meses antes da batalha. Quanto à mãe, Bartholomea, ela confirmou a data de 1449. Ela é segura, explica, pois, que sete meses após o nascimento o ano santo começou ${ }^{21}$. Enquanto o pai mobiliza-se institucionalmente para "salvar" seu filho ou se salvar, somente a mãe é depositária da origem da criança.

O nono artigo considera a legislação local, segundo a qual a idade de mais de dez anos deve ser entendida como o décimo primeiro ano, mas Benincasa não entra nesta categoria, pois ele tem menos de dez anos. O décimo artigo, enfim, enuncia que, considerando tudo o que foi dito antes, o processo contra Benincasa deve ser anulado. As testemunhas ou não foram interrogadas sobre esses dois últimos artigos, ou, quando o foram, não se pronunciaram, não se autorizando, mais uma vez, a se substituir ao juiz.

Através dos interrogatórios, o pai e a mãe, então, mobilizaram outros pais. Todos consideraram que o acidente fazia parte do risco do jogo, como em muitas comunas italianas da época. Todos esses pais que testemunharam e defenderam explicitamente Beneamato e seu filho e implicitamente a legitimidade do ludus, não vieram também, nostálgicos, defender uma atividade que eles perderam ou que eles estão perdendo, já que no século XV esses jogos sob controle são reservados exclusivamente às crianças? Eles protegem arduamente seus filhos que lançam pedras que eles não podem mais jogar. Os filhos tornados, por eles agora desarmados, referências. Como escreveu Pierre Legendre "[...] um pai é um filho que faz a função de pai” (LEGENDRE, 2000, p. 48). Sobre a cena comunal, os pais seguiam o jogo do qual eles foram destituídos sob 
outra forma, com outras armas. Através deste inquérito, um jogo de pedras virou um jogo de pais. Eles lançaram palavras. As palavras substituíram as pedras. Desse ponto de vista, as autoridades comunais conseguiram disciplinar os citadinos.

\section{Normas, práticas e legitimação}

Analisamos aqui um acontecimento, uma contração, que se inscreve certamente nas estruturas, mas que não é do cotidiano (mesmo se as crianças tivessem sido feridas antes): um acontecimento extraordinário e único (mesmo se ele se inscreve no seio do que nós podemos chamar de rito), que coloca em cena atores, eles mesmos únicos, em sua essência e suas relações. O acontecimento participa da atualização das estruturas e da atualização do ideal, isto é, o que os atores, antes mesmo de agir, pensam da batalha, das normas ou dos processos. Podemos legitimamente pensar que os dois acréscimos da rubrica estatutária (que diminuem a inimputabilidade das crianças na estrutura) foram consecutivos a acontecimentos do mesmo tipo e que atualizaram a norma. Esse lançar de pedra e o crânio esmagado são mais que acontecimentos, pois são ações que participam da criação de uma estrutura. Marshall Shalins chama nossa atenção sobre o que há de estrutural no acontecimento contingente, defendendo a ideia de uma "estrutura da conjuntura". Um acontecimento é uma atualização única de um fenômeno geral, uma realização contingente do modelo cultural. Existe uma ordem cultural constituída em cada sociedade e uma ordem cultural tal qual vivida pelos indivíduos: “[...] em seus projetos concretos e seus arranjos sociais, informados de significações reconhecidas de seres e de coisas, os homens produzem riscos empíricos às categorias culturais" (SHALINS, 1989, p. 9).

Os atores compreenderam como funciona o poder comunal. Eles conheciam perfeitamente as regras do jogo: o pai da vítima "denuncia" e o pai do acusado mobiliza um processo inquistorial. Eles perpetuam normas a partir do momento em que tentam conhecê-las melhor. As autoridades comunais consideram esse affaire, esta "prática", que conheceu uma "tradução jurídica" nas normas, como sem dúvida outros processos anteriores legitimaram as modificações das 
Construir e legitimar a autoridade paterna e comunal em um processo...

rubricas dos estatutos de 1426. As práticas são, então, produtoras de normas. Essas não são fixadas, elas evoluem sem cessar:

Socialmente, não há prova que no interior de dispositivos institucionais organizam a interação dos protagonistas em torno de procedimentos de validação para estabelecer uma verdade antes idealmente da forma de uma evidência compartilhada, em todo caso, aquela de um reconhecimento público sancionado (NAEPELS, 2009, p. 2).

Como vemos, o conceito de legitimação é mais operante que aquele de manipulação para explicar o comportamento dos atores face às normas. "Em relação ao paradigma da manipulação, o tema da legitimação coloca mais diretamente o problema - subestimado no outro conceito - da reprodução das normas sociais e das operações individuais da construção do coletivo" (CERUTTI, 1995, p. 132).

\section{Considerações finais}

Este estudo de caso permite realizar uma reflexão sobre alguns "conjuntos conceituais" (a comunidade, as estruturas familiares, a memória, o espaço e a constituição das normas) e algumas formas de comunicação (a linguagem e os rituais). Para defender-se ou para proteger seus próximos, os atores sociais utilizam as normas estatutárias e engrenagens jurídicas em uso na comuna. Enquanto utilizadores, eles participam da atualização dessas normas e da construção da aceitação desse poder. No exemplo estudado, assistimos a uma aceitação social coletiva dos pais. Não há recurso em causa, mas uma vontade de usar as possibilidades ofertadas. Compreendemos, assim, o aporte essencial de um estudo micro-histórico enquanto trata-se de compreender a dialética entre as normas e as práticas. Este método propõe "uma aproximação dinâmica da constituição do laço social" e permite sobrepor "a oposição factível entre regularidade institucional e inventividade social" e de substituir a oposição tradicional e pouco operante 
autoridade-resistência pelas noções de circulação, negociação e de apropriação (RICOEUR, 2000, p. 282).

Nesse documento, existem múltiplas figuras de autoridade e de poderes "legitimantes": o pai da vítima que faz a denúncia, o pai do acusado, a mãe da criança (única testemunha feminina do processo, que é convocada para provar a idade da criança), os pais de outras crianças da comuna das quais a instituição solicita as lembranças, as autoridades comunais (o podesta) que instruem o processo (e que pronunciaram a sententia, infelizmente perdida), as normas estatutárias e os representantes do papado. Não sabemos se Andrea di Nicola, a criança que teve a fratura craniana, sobreviveu aos ferimentos nem se Benincasa de Beneamato pôde se beneficiar da clemência da justiça podestária. Resta-nos, então, imaginá-los, um e outro, em agosto de 1459, em uma bataglia feroz.

\section{BUILD AND LEGITIMIZE FATHER'S AND COMUNAL'S AUTHORITY IN A TRIAL IN SAN SEVERINO (MARCHE) IN THE MIDDLE OF THE FIFTEENTH CENTURY}

Abstract: In August 1458, in San Severino (Marche of Ancona), during a gioco della battagliola, battle of stones very ritualized in which the children of the city fight against each over, a child is seriously wounded. The victim's father triggers an inquisitorial trial, forcing the guilty's one to come, with witnesses, to defend his son, trying to prove, among other things, that her child, under the age of ten years, is not legally responsible. This paternal defense shows that to protect their kinfolk, social actors use the statutory norms and legal machinery set up by the municipality. It also allows us to observe the manifestations of various authority figures and uncover the various instances of explicit or implicit legitimation. This type of event built paternal authority and communal's authority. This study of micro-history still can reveal, all the representations, rules of conduct, values attached to the person or to the actions, major components "ideational" of social life, and to question the relevance of a sweeping opposition between norms and practices. Keywords: Italy. Authority. Norms/practices. 
Construir e legitimar a autoridade paterna e comunal em um processo...

\section{Notas}

${ }^{1} \mathrm{O}$ texto encontra-se nos arquivos de São Severino: Archivio Storico Comunale di San Severino. Liber mallefitiorum offitii potestaire Antonii de Salamacchis de Civitate Castelli pro uno anno 1457 et MCCCCLVIIII (Nas próximas citações: ASCS, Liber mallefitiorum), fol. 204-207v. Ele foi, em parte, transcrito por PACIARONI (2009, 45-51): "getta seu maza flonda [...] fractura ossis seu cranei capitis [...] cum maxima sanguinis effuxione". ASCS, Liber mallefitiorum, fol. 204.

${ }^{2}$ Non sit/etatis ultra decem annorum, ASCS, Liber mallefitiorum, fol. $204 \mathrm{v}$.

${ }^{3}$ Gonfalonier de l'Eglise, expressão utilizada pelo autor do texto. Na Idade Média, correspondia ao cargo de chefe e/ou protetor da cidade, nomeado pelo Papa. N. do T. ${ }^{4}$ Nos estatutos de Ascoli Piceno (1377), perto de São Severino, o legislador proibiu "a battaglia das crianças, jovens e adultos "aos domingos, feriados e outros dias no campo de Paregnano (periferia de Ascoli Piceno) e em outros lugares no entorno da cidade, sob pena de uma multa de cinco livros. Se tivesse "porte de armas de metal ou de ferro", a multa era duplicada. Aquele que portasse uma funda (gecto overo floncha) na cidade era passível de uma multa de cem soldos (correspondente a cinco livros). STATUTI DI ASCOLI PICENO, 1999, livro III, 99, 120 - De quilli che fanno bactagla et chi porta la fioncha per cità.

5 “[... o direito tira sua origem do fato". N. do T.

${ }^{6}$ ASCS, Liber statutorum terre Sanctiseverini (1426), lib. II, rub. 80, fol. 75.

${ }^{7}$ Como é o caso, por exemplo, nos estatutos de Verona, nos quais, na margem, "uma mão" acrescentou em letras cursivas as modificações operadas em cada rubrica (BIANCHI; GRANUZZO, 1992, p. 73).

${ }^{8}$ Hans Keller e sua equipe de Münster estudaram esse trabalho de reelaboração que permite também facilitar a consulta aos estatutos no dia a dia (KELLER ; BUSCH, 1991).

${ }^{9}$ As menções a espaços suburbanos proibidos ou autorizados é frequente. Encontramos também para Pavia, Lucca, Milão, Modena, Ferrara ou Perúgia, (SETTIA, 1990, p. 91). Diferentemente, em Florença, as batalhas aconteciam nos espaços liminares, de fronteira, mas também no espaço urbano: sobre pontes e praças suburbanas (ZORZI, 1993, p. 76).

${ }^{10}$ Andrea Zorzi mostrou que no século XV, sobretudo nos Estados territoriais, as penas corporais reduziram em relação aos banimentos não apenas para os crimes políticos mas igualmente para os delitos correntes. ZORZI, 1993, parágrafo 23. ${ }^{11}$ O primeiro acréscimo começa com "Addimus hiic capitulo quod [...]" e, o segundo, com "Ac etiam addimus et presenti lege firmamus quod [...]". ASCS, Liber statutorum terre Sanctiseverini (1426), lib. II, rub. 80, fol. 75.

${ }^{12}$ Citado por SETTTA, 1990, p. 127. A título de comparação, eis uma passagem contemporânea e geograficamente próxima (ao sul de Ancona), de uma rubrica

Anos 90, Porto Alegre, v. 20, n. 38, p. 249-270, dez. 2013 


\section{Didier Lett}

dos estatutos de Sirolo (datados de 1465) intitulada: "Della pena de putti che saranno minori di diece anni": "Statuto, et determinato, è, che si alcun putto minor di diece, commeterrà alcun delitto o maleficio, mancando di discrettione non deva esser condannato in cosas alcuna ma si serà maggiore di anni diece insino al quarto decimo inclusive et commetterà alcun delli detti maleficii, et delitti si condamni in mezza pena, et manco all'arbitrio dellófficiale, considerata la qualità dell'età et del delitto". (GAUDENTI, 1938, capítulo 19, p. 122)

${ }^{13}$ In terra Sancti/Severini fuit semper consuetus fieri prelium inter pueros et de vulneribus factis/in dictis prelis nunquam audivit quod aliqua pena fuerit soluta adeo quod quidam de/dicta terra fuit interfectus in dicto prelio et numquam fuit facta aliqua inquisitio/per curiam contra interficientem et etiam ipse testis fuit vulneratus in dicto prelio et/non fuit imposita aliqua pena vulneranti.

${ }^{14}$ Jean Bazin escreveu que "les récits que nous enregistrons aujourd'hui peuvent être en fait le sédiment d'historisations successives dont chacune avait pour but de 'ré-écrire' l'histoire en fonction des intérêts du moment". (BAZIN, 1979, p. 470). ${ }^{15}$ Encontramos esses fundamentos no Digesta: "Si quis per iocum percutiat aut dum certat, iniuriarum non tenetur". Conferir a citação feita por Settia (1990, p. 125) desta passagem.

16 "Dixit quod anno presenti et mense augusti pluribus vicibus fuit factum prelium inter pueros". Encontramos essa fórmula nos testemunhos de Ansovino di Severino (fol. 206), Nicola di Oliviero (fol. 206 v.), Lucarello di Bartholomeo (fol. 206 v.). 17 "Inter(r)ogatus de loco dixit extra portam Vallis in quadam possessionne Johannis Patritii juxta bona/Johannis Cristofori, bona Sancti Salvatoris et alios fines". (ASCS, Liber mallefitiorum, folio 206v)

18 "dixit/ que dum ipse Andrea fuit vulneratus audivit voces multorum puerum/ ibi existentium et dicentium: 'bambacio, bambacio, che è ferito lu figlio de Nicola”. (ASCS, Liber mallefitiorum, fol. 206. As crianças pedem, sem dúvida, que lhes entreguem algodão, para estancar a hemorragia de Andrea di Nicola.

19 "Interrogatus super 7 et 8 dixit quod dictus Benemcasa est minor decem annorum/et ita tenetur et reputatur. Interogatus in causa scientie dixit quod dum ipse testis duxit/uxorem et sunt jam otto anni mater dicti Benemcase intervenit in nuttis ipsius testis/ et habebat dictum Benemcasam in brachiis et apparebat quod dictus Benemcasa non erat/etatis duorum annorum". (ASCS, Liber mallefitiorum, folio $206 \mathrm{v}$ )

20 "Item/interrogatus super 7 et 8 dixit quod dictus Benemcasa est minor decem annorum./Interrogatuso in causa scientie dixit se bene recordari de nativitate dicti Benemcase qui/ natus fuit in anno 1449 et mense junii et uxor ipsius testis ivit/ ad vigitandum matrem dicti Benemcase dum erat in partu et in lecto propter/ navitatem dicti Benemcase et ita dixit dictus Benemcasa haberi et reputari/ pro minore decem annorum". (ASCS, Liber mallefitiorum, folio 207)

Anos 90, Porto Alegre, v. 20, n. 38, p. 249-270, dez. 2013 
Construir e legitimar a autoridade paterna e comunal em um processo...

21 "Interogata super settimo et 8 dixit quod dictus benemcasa/ de quo fit mentio in dicto capitulo est minor decem annorum et ipsa testis/ peperit dictum Nenemcasam in anno 1449 et de mense junii dicti anni//. Interrogata qualiter ipsa recordatur de tempore dixit que expleto dicto anno in quo ipsa/ perperit dictum Benemcasam incepit annus santum videlicet post partum suum per settem/ menses vel circha. Interogata in causa scientie dixit que ipsa testis perperit dictum/ Benemcasam ut supra et ex corpore suo dictus Benemcasa natus fuit". (ASCS, Liber mallefitiorum, folio 208-208v).

\section{Referências}

ARCHIVIO STORICO COMUNALE DI SAN SEVERINO LIBER MALLEFITIORUM OFFITII POTESTARIE ANTONII DE SALAMACCHIS DE CIVITATE CASTELLI PRO UNO ANNO 1457 ET MCCCCLVIIII (ASCS, Liber mallefitiorum), fol. 204-207 v.

BAIETTO, Laura. Elaborazione di sistemi documentari e trasformazioni politiche nei comuni piemontesi (secolo XIII): una relazione di circolarità . Società e storia, n. 98, p. 645-679, 2002.

BAZIN, Jean. La production d'un récit historique. Cabiers d'études africaines (Gens et paroles d'Afrique. Ecrits pour Denise Paulme), v. 19, n. 73-76, p. 435-484, 1979.

. Le bal des sauvages, dans Le sauvage est à la mode, J. L. Amselle (Dir.), Paris: Le Sycomore, p. 179-218, 1979. repris dans ID., Des Clous dans la Joconde. L'anthropologie autrement, Paris: Anacharsis, p. 51-98, 2008.

BEDELL, John. Memory and Proof of Age in England 1272-1327. Past and Present, n. 162, p. 3-27, fev. 1999.

BENSA, Alban. De la culture et du mythe comme artefacts dans ID., La fin de l'exotisme. Essais d'anthropologie critique. Paris: Anacharsis, p. 123-138, 2006.

BOLTANSKI, Luc. L'amour et la justice comme compétences. Trois essais de sociologie de l'action. Paris: Métailé, 1990.

CAMMAROSANO, Paolo. Italia medievale. Struttura e geografia delle fonti scritte. Rome, 1991, rééd., 2000.

CERUTTI, S. Normes et pratiques, ou de la légitimité de leur opposition. In: LEPETIT, Bernard. (Dir). Les Formes de l'expérience. Une autre histoire sociale. Paris: Albin Michel, 1995, p. 127-149.

CHAUVIER, Eric. Anthropologie de l'ordinaire. Une conversion du regard. Paris: Anacharsis, 2011.

Anos 90, Porto Alegre, v. 20, n. 38, p. 249-270, dez. 2013 


\section{Didier Lett}

GIANANDREA, Antonio. Della Signoria di Francesco Sforza nella Marca secondo le memorie e documenti dell'archivio settempedano \{San Severino\}. Milan, 1885, rééd., 1978. GLI STATUTI DI VERONA DEL 1327. A cura di S. A. Bianchi et R. Granuzzo, 2 volumes, Rome, Jouvence, 1992.

GLI STATUTI DEL COMUNE DI SIROLO DEL 1465 E LORO SUCCESSIVE RIFORMAZIONI, A cura di Alberto Canaletti Gaudenti. Ancône, 1938. GUYOTJEANNIN, Olivier; Morelle, Laurent; Parisse, Michel. Pratiques de l'écrit documentaire au XI' siècle, Chartres: Bibliothèque de l'Ecole des Chartes, 1997, p. 155.

JANSEN, Philippe. Démographie et société dans les Marches à la fin du Moyen Âge. Macerata aux XIV et XV siècles (Collection de l'École française de Rome-279). Rome, 2001.

La territorialité des villes marchésanes à la fin du Moyen Âge d'après les ambassades. In: BARTHELEMY, Dominique; MARTIN, Jean-Marie (Dirs). Liber largitorius. Etudes d'histoire médiévale offertes à Pierre Toubert par ses élèves. Genebra: Droz, 2003, p. 195-218.

KELLER, Hans; BUSCH, Jorg. (Dirs). Statutencodices des 13. Jabrbunderts als Zeugen pragmatischer Schriftlichkeit. Die Handschriften von Como, Lodi, Novara, Pavia und Voghera. Munique, 1991.

LEGENDRE, Pierre. Le Crime du caporal Lortie. Traité sur le père. Paris 1989, rééd. 2000 .

LEMIEUX, Cyril. Le Devoir et la grâce. Paris: Economica, 2009.

MAIRE VIGUEUR, Jean-Cleaude. Un jeu bien mal tempéré. Le ludus battaglie de Pérouse, dans Histoire et société. Mélanges offerts a Georges Duby, II: Le tenancier, le fidèle et le citoyen. Aix-en Provence: Publications de l'université de Provence, 1992, p. 195-208.

MAFFEI, Elena. Dal reato alla sentenza. Il processo criminale in età comunale. Roma: Edizioni di Storia e Letteratura, 2007.

MANSELLI, Raoul. Il sistema degli stati italiani dal 1250 al 1454 dans Comuni e signorie: istituzioni, società e lotte per l'egemonia, t. IV, Storia d'Italia UTET, Giuseppe Galasso dir., Turin, p. 179-265, 1981.

NAEPELS, Michel; BAckouche, Isabelle.(Dirs.) Faire la preuve, Genèses 74, Paris: Belin, 2009.

ORTALLI, Gherardo. Tempo libero e medio evo: tra pulsioni ludiche e schemi culturali. In: CAVACIOCCHI, Simonetta. (Org). Il tempo libero. Economia e società (Loisirs, Leisure, Tempo Libre, Freizeit, secc. XIII-XVIII) Florença: Le Monnier, p. 31-54, 1995.

Anos 90, Porto Alegre, v. 20, n. 38, p. 249-270, dez. 2013 
Construir e legitimar a autoridade paterna e comunal em um processo...

PACIARONI, Raoul. Il gioco della battagliola a San Severino e in altre città delle Marche. Associazione Palio dei Castelli, San Severino, Marche 2009.

POTIN, Yann; et THÉRY, Jean. L'histoire médiévale et la nouvelle érudition: l'exemple de la diplomatique, Labyrinthe, p. 35-39, avril/1999.

RICOEUR, Paul. La Mémoire, l’histoire, l'oubli. Paris: Seuil, 2000.

Rizzi, Alessandra. Le jeu dans les villes de l'Italie médiévale, Histoire urbaine, n. 1, p. 47-64, 2000/1.

. Ludus/ludere. Giocare in Italia alla fine del Medio Evo. Rome: Viella, 1995.

SAHLINS, Marshal. Des îles dans l’histoire, Paris: Gallimard-Seuil,1989.

SETTIA, Aldo. A. Ut melius doceantur ad bellum: i giochi di guerra e l'addestramento delle fanterie comunali, In: La civiltà del torneo (sec. XII-XVII). Giostre e tornei fra medioevo ed età moderna Narni: Centro studi storici di Narni, 1990, p. $79-105$.

- Il gioco pubblico in Italia. Storia, cultura e mercato, a cura di G. Imbucci: Università degli Studi di Salerno, Dipartimento di Scienze Storiche e Sociali, Marsilio, 1999.

. Il tempo libero. Economia e società (Loisirs, Leisure, Tempo Libre, Freizeit, secc. XIII-XVIII), a cura di Simonetta Cavaciocchi, Florence, Le Monnier, 1995.

STATUTI DI ASCOLI PICENO. BRESCHI, Giancarlo; VIGNUZZI, Ugo (Dir.), v. 1, Ascoli Piceno, 1999, livre III.

TADDEI, Ilaria. L'encadrement des jeunes à Florence au XV siècle. Histoire urbaine, p. 119-132, 2001.

WALEY, Daniel. Lo stato papale dal periodo feudale a martino V, Comuni e signorie nell'Italia nordorientale e centrale, t. VII, v. 2, GALASSO, Giuseppe (Dir.), Turin, p. 229-320, 1987.

ZORZI, Andrea. La politique criminelle en Italie (XIII'-XVII ${ }^{\mathrm{e}}$ siècles). Crime, Histoire e Sociétés / Crime, History \& Societies [En ligne], v. 2, n.2, 1998, mis en ligne le 03 avril 2009. Disponível em: < http://chs.revues.org/index972.html>. Data de acesso: mai. 2013.

- Battagliole e giochi d'azzardo a Firenze nel tardo Medioevo: due pratiche sociali tra disciplinamento e repressione, dans Gioco e giustizia nell'Italia di Comune, a cura di G. Ortalli, Treviso-Roma: Viella, p. 71-107,1997.

Recebido em: 30 de junho de 2013.

Aprovado em: 26 de setembro de 2013.

Anos 90, Porto Alegre, v. 20, n. 38, p. 249-270, dez. 2013 